\title{
The Eberhart and Russel's Bayesian method used as an instrument to select maize hybrids
}

\author{
Tâmara Rebecca Albuquerque de Oliveira • Hélio Wilson Lemos de Carvalho • \\ Moysés Nascimento - Emiliano Fernandes Nassau Costa • Antonio Teixeira do Amaral Junior • \\ Geraldo de Amaral Gravina · José Luiz Sandes de Carvalho Filho
}

Received: 1 September 2017/Accepted: 2 March 2018/Published online: 8 March 2018

(C) Springer Science+Business Media B.V., part of Springer Nature 2018

\begin{abstract}
Adaptability and stability analysis methods that use a priori information allow identifying and selecting potentially productive genotypes with greater accuracy. The aim of the current study is to use the Eberhart and Russel' Bayesian method as an instrument to analyze the adaptability and stability of hybrid maize cultivars and to assess the efficiency of using the distribution of informative and non-informative priors to select cultivars. Twenty-five (25) hybrid maize cultivars were assessed in 11 environments located in the Brazilian Northeastern region, during 2012 and 2013, according to a complete randomized block design, with two repetitions. The
\end{abstract}

T. R. A. de Oliveira $(\bowtie) \cdot$ A. T. do Amaral Junior .

G. A. Gravina

Universidade Estadual do Norte Fluminense Darcy

Ribeiro, Avenida Alberto Lamego, 2000 - Parque

California, Campos Dos Goitacazes, RJ 28035-200, Brazil

e-mail: tamara_rebecca@hotmail.com

H. W. L. de Carvalho - E. F. N. Costa

Embrapa Tabuleiros Costeiros, Avenida Beira Mar, 3250 -

Jardins, Aracaju, SE 49025-040, Brazil

M. Nascimento

Universidade Federal de Viçosa, Avenida Peter Henry

Rolfs, s/n - Campus Universitárioa, Viços,

MG 36570-900, Brazil

\section{J. L. S. de Carvalho Filho}

Universidade Federal Rural de Pernambuco, Rua Manoel de Medeiros, s/n - Dois Irmãos, Recife, PE 52171-900, Brazil
Eberhart and Russel's methodology was performed in the GENES software, whereas the Bayesian procedure was implemented in the free software R, by using the MCMCregress function of the MCMCpack package. The adaptability and stability parameters values and the credibility intervals have shown that the Eberhart and Russel's method via Bayesian technique has shown greater stability-estimation accuracy and greater efficiency in recommending cultivars adapted to favorable and unfavorable environments. The Bayesian methods using priories informative (M1) and few informative (M2) distributions have presented the same genotype classifications in the comparison between a priori distributions; however, according to the Bayes Factor, the M1 was the most adequate distribution to help finding more reliable estimates.

Keywords Bayes factor - Genotype $\times$ environment interaction - Informative priori - Zea mays $L$.

\section{Introduction}

The main goal of a hybrid maize breeding program is to identify hybrid combinations showing high productive potential, as well as good adaptability and stability.

However, the genotype $\times$ environment interaction is one of the major challenges faced during selection, since it makes it difficult to identify effectively 
superior genotypes. The diversity of cultivation environments is often responsible for the significant effect of the interaction between genotypes and environments $(\mathrm{G} \times \mathrm{E})$ (Engelsing et al. 2012).

Estimating this interaction is extremely important, because it reduces the probability of errors in genotype selection or recommendation (Backes et al. 2005; Mendes et al. 2012). Several frequentist methods estimate genotype adaptability and stability based on different principles; among them, the mixed models (REML/BLUP), as well as the models based on simple linear regression (Eberhart and Russell 1966; Cruz et al. 1989) and on segmented linear regression (Verma et al. 1978), and the non-parametric methods (Lin and Binns 1988) stand out.

Issues concerning the accuracy and precision of predictions and estimates cannot be completely solved through REML/BLUP, since the distribution and variance of the estimators are not known, thus generating approximate confidence intervals for the genetic parameters (Resende et al. 2001). On the other hand, the other frequentist methods predict the performance of the genotypes based on parameter estimates derived from a set of estimators.

Unlike these methods, the Bayesian inference has a single estimator that leads to estimates able to maximize the probability density function a posteriori. It makes it possible generating exact credible intervals for genetic parameter estimates and provides more rigor to the analyses; consequently, the genotype selection shows greater accuracy (Resende 2000).

Thus, on the Bayesian procedure, the parameters are interprets as random variables, where the probability models may shows initial information about these parameters, independent of what the data may show (Molina et al. 2012). Studies have shown the Bayesian methodology superiority to select genotypes in different environments, in comparison to frequentist methods (Silva and Benavides 2001; Cotes et al. 2006; Couto et al. 2015; Teodoro et al. 2015).

The Bayesian analysis have been used in plant breeding for present itself as a robust statistical procedure that shows information richness and the possibility of several applications (Bastiaansen et al. 2012; Almeida et al. 2016; Macedo et al. 2017).

In light of the foregoing, the aim of the current study was to use the Eberhart and Russel' Bayesian method as an instrument to analyze the adaptability and stability of maize hybrids and to assess the efficiency of using informative and non-informative a priori distributions to select cultivars.

\section{Materials and methods}

The experiments were carried out in Maranhão (Balsas, Brejo, Colinas and São Raimundo das Mangabeiras counties), Piauí (Nova Santa Rosa, Teresina and Uruçuí counties) and Sergipe states (Nossa Senhora das Dores, Frei Paulo and Umbaúba counties), during the agricultural years 2012 and 2013.

The experimental area in Nossa Senhora das Dores County was divided in two environments, which were characterized according to fertilization differences. The trials using high fertilization range comprised $180.00 \mathrm{~kg} \mathrm{ha}^{-1} \mathrm{~N}, \quad 149.80 \mathrm{~kg} \mathrm{ha}^{-1} \quad \mathrm{P}_{2} \mathrm{O}_{5}$ and $85.60 \mathrm{~kg} \mathrm{ha}^{-1} \mathrm{~K}_{2} \mathrm{O}$, whereas the trials using low fertilization range comprised $45.00 \mathrm{~kg} \mathrm{ha}^{-1} \mathrm{~N}$, $37.80 \mathrm{~kg} \mathrm{ha}^{-1} \mathrm{P}_{2} \mathrm{O}_{5}$ and $21.60 \mathrm{~kg} \mathrm{ha}^{-1} \mathrm{~K}_{2} \mathrm{O}$, in the form of 535 and $135 \mathrm{~kg} \mathrm{ha}^{-} 1$ of $8-28-16+\mathrm{Zn}$ at sowing time; both treatments received nitrogen cover in the form of urea 21 days after emergence. Twenty-two (22) environments, in total, were taken into consideration according to the edaphoclimatic differences in the different years, in the same sites.

Twenty-five (25) maize hybrids coming from public and private companies were assessed (Table 1). The experimental design was based on randomized blocks, with two repetitions, and the plots comprised four rows ( $5.0 \mathrm{~m}$ long), $0.70 \mathrm{~m}$ interrow spacing and $0.20 \mathrm{~m}$ spacing between holes within the rows. The fertilization was performed according to the results of the soil analysis performed in each experimental area. Irrigation was not carried out, whereas the weed and pest control was done according to the crop's need in each region.

The productivity data were subjected to analysis of variance. The joint analysis of variance was performed in the GENES software (Cruz 2006), after the homogeneity of the residual variances was found through the F maximum test by Hartley (1950). The joint analysis of variance has adopted the model $Y_{i j k}=\mu+R / \mathrm{E}_{\mathrm{k}(\mathrm{j})}+G_{i}+E_{j}+G E_{i j}+\varepsilon_{i j k}$, wherein: $\mathrm{Y}_{\mathrm{ijk}}$ is the mean phenotypic value of the plot; $\mu$ is the general constant; $R / E_{k}(j)$ is the effect of kth repetition in the jth environment; $G_{i}$ is the fixed effect of the ith genotype; $E_{j}$ is the effect of the jth environment NID $\left(0, \sigma_{\mathrm{E}}^{2}\right), \mathrm{GE}_{\mathrm{ij}}$ is the effect of the ith genotype 
Table 1 List of hybrid maize cultivars and their respective origins, types, cycles, colors, grain textures and companies

\begin{tabular}{|c|c|c|c|c|c|c|}
\hline Cultivar & Transgenic/conventional & Type & Cycle & Grain color & Grain texture & Company \\
\hline 30 A 95 HX & Transgenic & $\mathrm{TH}$ & $\mathrm{E}$ & OR & SMHARD & MORGAN \\
\hline 30 A 68 HX & Transgenic & SH & $\mathrm{EE}$ & OR & SMHARD & MORGAN \\
\hline BM 820 & Conventional & SH & $\mathrm{E}$ & $\mathrm{R}$ & HARD & BIOMATRIX \\
\hline DKB $330 \mathrm{YG}$ & Conventional & SH & $\mathrm{EE}$ & $\mathrm{R} / \mathrm{OR}$ & SMDENT & DEKALB \\
\hline AS 1596 R2 & Transgenic & SH & $\mathrm{E}$ & $\mathrm{R}$ & SMDENT & AGROESTE \\
\hline P $4285 \mathrm{H}$ & Transgenic & SH & $\mathrm{E}$ & Y/OR & HARD & DU PONT \\
\hline 2 B 710 HX & Transgenic & SH & $\mathrm{E}$ & Y/OR & SMHARD & DOW \\
\hline 30 A $16 \mathrm{HX}$ & Transgenic & SH & $\mathrm{E}$ & OR & SMHARD & MORGAN \\
\hline DKB 370 & Conventional & $\mathrm{SHm}$ & $\mathrm{E}$ & Y/OR & SMHARD & DEKALB \\
\hline AG 8041 YG & Transgenic & SH & $\mathrm{E}$ & Y/OR & SMHARD & SEMENTES \\
\hline 20 A 55 HX & Transgenic & $\mathrm{TH}$ & $\mathrm{E}$ & OR & SMHARD & MORGAN \\
\hline $30 \mathrm{~F} 53 \mathrm{HR}$ & Transgenic & SH & $\mathrm{E}$ & OR & SMHARD & DU PONT \\
\hline 30 A 37 HX & Transgenic & SH & $\mathrm{EE}$ & Y/OR & SMHARD & MORGAN \\
\hline 30 A $91 \mathrm{HX}$ & Transgenic & $\mathrm{SHm}$ & $\mathrm{E}$ & Y/OR & SMHARD & MORGAN \\
\hline 2 B 587 HX & Transgenic & SH & $\mathrm{E}$ & Y/OR & SMDENT & DOW \\
\hline 2 B $433 \mathrm{HX}$ & Transgenic & $\mathrm{TH}$ & $\mathrm{EE}$ & Y/OR & SMDENT & DOW \\
\hline AS 1555 YG & Transgenic & $\mathrm{SH}$ & $\mathrm{E}$ & OR & SMHARD & AGROESTE \\
\hline BRS 2022 & Conventional & $\mathrm{DH}$ & $\mathrm{E}$ & OR & SMDENT & EMBRAPA \\
\hline STATUSVIP & Transgenic & $\mathrm{SH}$ & $\mathrm{E}$ & OR & HARD & SYNGENTA \\
\hline BRS 2020 & Conventional & $\mathrm{DH}$ & $\mathrm{E}$ & OR & SMHARD & EMBRAPA \\
\hline 2 B 707 HX & Transgenic & $\mathrm{SH}$ & $\mathrm{E}$ & OR & SMHARD & DOW \\
\hline 20 A 78 HX & Transgenic & SH & $\mathrm{E}$ & OR & SMHARD & DOW \\
\hline 2 B 604 HX & Transgenic & $\mathrm{SHm}$ & $\mathrm{E}$ & OR & SMHARD & DOW \\
\hline $30 \mathrm{~K} 73 \mathrm{H}$ & Transgenic & $\mathrm{SH}$ & $\mathrm{E}$ & Y/OR & SMHARD & DU PONT \\
\hline 2 B 688 HX & Transgenic & $\mathrm{TH}$ & $\mathrm{E}$ & OR & SMHARD & DOW \\
\hline
\end{tabular}

Type: $D H$ double hybrid, $T H$ triple hybrid, $S H m$ modified single hybrid; Cycle: $E E$ extra early, $E$ early; Grain color: $O R$ orange, $R$ reddish, $Y$ yellow; Grain texture: SMDENT semi-dent, SMHARD semi-hard

interaction in the jth environment NID $\left(0, \sigma_{\mathrm{GE}}^{2}\right)$ and, $\varepsilon_{\mathrm{ijk}}$ is the experimental error NID $\left(0, \sigma^{2}\right)$.

The Bayesian analysis considered the values resulting from the frequentist analysis as a priori information, wherein the hypotheses $\mathrm{H}_{0}: \beta_{1 i}=1$ and $\mathrm{H}_{1}: \beta_{1 i} \neq 1$, for adaptability; and $\mathrm{H}_{0}: \sigma_{\mathrm{di}}^{2}=0$ and $\mathrm{H}_{1}: \sigma_{\mathrm{di}}^{2}>$, for stability, were assessed through $\mathrm{t}$ and $\mathrm{F}$ statistics, respectively (Teodoro et al. 2015). The use of values resulting from the frequentist analysis as a priori information was necessary since the genotypes evaluated in this work does not present any information about the regression parameters in the literature. This approach, called Empirical Bayes, was used by Kitada et al. (2000) and Wang et al. (2016). However, if this information have been available, as Nascimento et al.
(2011) and Couto et al. (2015), we should use information from previous studies.

The method by Eberhart and Russell (1966) is based on simple regression analysis, in which adaptability, or the linear response to the environments, is given by the $\beta_{1 i}$ parameter estimate and by the mean productivity $\beta_{0 i}$, whereas stability is found through the regression deviation $\delta_{i j}$, according to the statistical model used in experiments involving $g$ genotypes, $e$ environments and $r$ repetitions: $Y_{i j}=\beta_{0 i}+\beta_{1 i} I_{j}+$ $\delta_{i j}+\bar{\varepsilon}_{i j}$, wherein $Y_{i j}$ is the response of genotype $i$ in the environment $j ; \beta_{0 i}$ is the response of genotype $\mathrm{i} ; \beta_{1 i}$ is the regression coefficient measuring the ith genotype response to the environment variation; $I_{j}$ is the 
coded environmental index; $\delta_{\mathrm{ij}}$ is the regression deviation and $\bar{\varepsilon}_{i j}$ is the mean experimental error.

If one considers the statistical model $Y_{i j}=\beta_{0 i}+$ $\beta_{1 i} I_{j}+\delta_{i j}+\bar{\varepsilon}_{i j}$ in the Bayesian approach, and assumes that each $\mathrm{Y}_{\mathrm{ij}}$ observation has a $\mathrm{Y}_{\mathrm{ij}} \sim \mathrm{N}\left(\beta_{0 i}+\beta_{1 i} I_{j}\right.$ : $\left.\sigma_{i}^{2}\right)$ distribution, the probability function for each genotype $i$ is given through (Nascimento et al. 2011):

$$
\begin{aligned}
& L_{i}\left(\beta_{0 i}, \beta_{1 i}, \sigma_{i}^{2}, Y_{i j}\right)=\prod_{j=1}^{a} \frac{1}{\sqrt{2 \pi \sigma_{i}^{2}}} \\
& \quad \exp \left\{-\frac{1}{2 \sigma_{i}^{2}}\left[Y_{i j}-\left(\beta_{0 i}+\beta_{1 i} I_{j}\right)\right]^{2}\right\} \\
& =\frac{1}{\left(\sqrt{2 \pi \sigma_{i}^{2}}\right)^{a}} \exp \left\{-\frac{1}{2 \sigma_{i}^{2}} \sum_{j=1}^{a}\left[Y_{i j}-\left(\beta_{0 i}+\beta_{1 i} I_{j}\right)^{2}\right]\right\}, \forall_{i}
\end{aligned}
$$

It is necessary assigning the a priori distributions to the parameters in order to estimate their adaptability and stability. The following distributions were taken into consideration for $\beta_{0 i}, \beta_{1 i}$ and $\sigma_{i}^{2}: \beta_{0 i} \sim N\left(\mu_{0 i}, \sigma_{0 i}^{2}\right)$, $\beta_{1 i} \sim N\left(\mu_{1 i}, \sigma_{1 i}^{2}\right), \quad \sigma_{i}^{2} \sim \operatorname{GamaInv}\left(\alpha_{i}, \beta_{i}\right)$; the $\sigma_{i}^{2} \sim \operatorname{GamaInv}\left(\alpha_{i}, \beta_{i}\right)$ distribution comprised an inverse range with mean and variance equal to $\frac{\beta_{i}}{\alpha_{i}}$ and $\frac{\beta_{i}^{2}}{\left(\alpha_{i}-1\right)^{2}\left(\alpha_{i}-2\right)}$, respectively (Nascimento et al. 2011).

If one assumes independence between the parameters of these distributions, the a priori joint distribution for each genotype is given through (Nascimento et al. 2011):

$$
\begin{aligned}
P_{i}\left(\beta_{0}, \beta_{1 i}, \sigma_{i}^{2}\right)= & \frac{1}{\sqrt{2 \pi \sigma_{0 i}^{2}}} \exp \left\{-\frac{1}{2 \sigma_{0 i}^{2}}\left(\beta_{0 i}, \mu_{0 i}\right)^{2}\right\} \\
& \times \frac{1}{\sqrt{2 \pi \sigma_{1 i}^{2}}}
\end{aligned}
$$

$$
\begin{aligned}
& \exp \left\{-\frac{1}{2 \sigma_{1 i}^{2}}\left(\beta_{1 i}, \mu_{1 i}\right)^{2}\right\} \\
& \quad \times \frac{1}{\left(\beta_{i}^{\alpha_{i}} G\left(\alpha_{i}\right)\right)}\left(\frac{1}{\sigma_{i}^{2}}\right)^{\alpha_{i}+1} \exp \left\{-\frac{1}{\beta_{i} \sigma_{i}^{2}}\right\} \\
& \propto \exp \left\{-\frac{1}{2 \sigma_{i}^{2}}\left(\beta_{0 i}, \mu_{0 i}\right)^{2}\right\} \\
& \quad \times \frac{1}{\sqrt{2 \pi \sigma_{1 i}^{2}}} \exp \left\{-\frac{1}{2 \sigma_{1 i}^{2}}\left(\beta_{1 i}, \mu_{1 i}\right)^{2}\right\} \\
& \quad \times\left(\frac{1}{\sigma_{i}^{2}}\right)^{\alpha_{i}+1} \exp \left\{-\frac{1}{\beta_{i} \sigma_{i}^{2}}\right\}
\end{aligned}
$$

It is necessary finding the marginal a posteriori distributions of the parameters of interest in order to make inferences about them. If one denotes the parameter vector for each genotype $i$ through $\theta_{\mathrm{pi}}=\left(\beta_{1 \mathrm{i}}, \beta_{2 \mathrm{i}}\right.$, $\sigma_{\mathrm{i}}^{2}$ )—wherein $\mathrm{p}=1,2,3$ - then, the marginal a posteriori distribution for the $\theta_{\mathrm{pi}}$ parameter is found through the following integral: $\mathrm{P}\left(\theta_{\mathrm{pi}} \mid \mathrm{x}\right)=\int \mathrm{P}\left(\theta_{\mathrm{pi}} \mid \mathrm{x}\right) \mathrm{d} \theta_{\mathrm{pi}}$, which refers to the integral of all vector parameters, except for the pth component.

The methodology adopted in the present study was implemented in the $\mathrm{R}$ software (The $\mathrm{R}$ Foundation 2010), whereas the joint distribution sample was obtained through the MCMCregress function of the MCMCpack package. The Bayes Factor was calculated using the BayesFactor function of the MCMCpack package. This factor may vary from less than 1 to more than or equal to 100 , wherein $\mathrm{BFij}<1$ shows evidence in favor of model $\mathrm{j} ; 1 \leq \mathrm{BFij}<3$ shows moderate evidence in favor of model $\mathrm{i} ; 3 \leq \mathrm{BFij}<10$ shows substantial evidence in favor of model $\mathrm{i}$; $10 \leq \mathrm{BFij}<30$ shows strong evidence in favor of model $\mathrm{i} ; 30 \leq \mathrm{BFij}<100$ shows very strong evidence in favor of model $\mathrm{i}$; and $\mathrm{BFij} \geq 100$ shows decisive evidence in favor of model i (Jeffreys 1961).

Informative a priori distributions, whose information derived from the frequentist analysis considering all the assessed genotypes, were used in the first model (M1) to perform the Bayesian analysis. The information was inserted in the analysis through the values assumed for the a priori distribution parameters, named hyperparameters.

These values were found through the mean and variance of the sample composed of the parameter estimates found in the frequentist analysis, which resulted in the following distributions: $\beta_{0 i} \sim N$ $\left(\mu_{0 i}=\bar{\beta}_{0 i}, \sigma_{0 i}^{2}=\operatorname{Var}\left(\bar{\beta}_{0 i}\right)\right), \quad \beta_{1 i} \sim N\left(\mu_{1 i}=\bar{\beta}_{1 i}, \sigma_{1 i}^{2}=\right.$ $\left.\operatorname{Var}\left(\bar{\beta}_{1 i}\right)\right)$ and $\sigma_{i}^{2} \sim \operatorname{GamaInv}\left(\alpha_{i}, \beta_{i}\right)$, wherein: $\bar{\beta}_{0 i}$ is the $\beta_{0 i}$ estimates; $\bar{\beta}_{1 i}$ is the $\beta_{1 i}$ estimates; $\operatorname{Var}\left(\bar{\beta}_{0 i}\right)$ is the variance of $\beta_{0 i}$ values; $\operatorname{Var}\left(\bar{\beta}_{1 i}\right)$ is the variance of $\beta_{1 i}$ values; and $\alpha_{i}$ and $\beta_{i}$ are values obtained from the system equation:

$$
\begin{gathered}
E\left(\bar{\sigma}_{i}^{2}\right)=\frac{\beta_{i}}{\alpha_{i}-1} \\
\operatorname{Var}\left(\bar{\sigma}_{i}^{2}\right)=\frac{\beta_{i}^{2}}{\left(\alpha_{i}-1\right)^{2}+\left(\alpha_{i}-2\right)}, \text { which were: } \\
\alpha_{i}=2 \times \frac{E\left(\bar{\sigma}_{i}^{2}\right)^{2}}{V\left(\sigma_{i}^{2}\right)}+2, \quad \beta_{i}=2 \times \frac{E\left(\bar{\sigma}_{i}^{2}\right)^{3}}{V\left(\sigma_{i}^{2}\right)}+1
\end{gathered}
$$


The second model (M2) used slightly informative a priori distributions, which represented probability distributions showing great variance. The following distributions were herein adopted: $\beta_{0 i} \sim N\left(\mu_{0 i}=0\right.$, $\left.\sigma_{0 i}^{2}=1,000,000\right), \beta_{1 i} \sim N\left(\mu_{1 i}=0, \sigma_{1 i}^{2}=1,000,000\right)$ and $\sigma_{i}^{2} \sim \operatorname{GamaInv}\left(\alpha_{i}=0.0001 ; \beta_{i}=5.000\right)$.

The comparison between M1 and M2, i.e., between informative and non-informative a priori distributions, was based on the Bayes Factor (BF) (Kass and Raftery 1995).

The Bayes Factor was calculated through the BayesFactor function of the MCMCpack package. According to Jeffreys (1961), the Bayes Factor may be interpreted as follows: $\mathrm{BF}_{\mathrm{ij}}<1$ shows evidence in favor of model $\mathrm{j} ; 1 \leq \mathrm{BF}_{\mathrm{ij}}<3$ shows moderate evidence in favor of model $\mathrm{i} ; 3 \leq \mathrm{BF}_{\mathrm{ij}}<10$ shows substantial evidence in favor of model $\mathrm{i} ; 10 \leq \mathrm{BF}_{\mathrm{ij}-}$ $<30$ shows strong evidence in favor of model $\mathrm{i}$; $30 \leq \mathrm{BF}_{\mathrm{ij}}<100$ shows very strong evidence in favor of model $\mathrm{i}$; and $\mathrm{BF}_{\mathrm{ij}} \geq 100$ shows decisive evidence in favor of model $\mathrm{i}$.

The marginal distribution samples of the stability parameter $\left(\sigma_{d i}^{2}\right)$ were indirectly obtained, since this parameter represents a $\sigma_{i}^{2}$ function. If one indirectly finds $\sigma_{d i}^{2}$ values in each interaction, it is possible finding $\sigma_{d i}^{2}$ values through the following expression: $\widehat{\sigma}_{d i}^{2}=\widehat{\sigma}_{i}^{2}-(M S R / r)$, wherein: MSR is the mean square residue provided by the analysis of variance, and $r$ is the number of repetitions in the experiment.

The hypotheses of interest were tested through the construction of credible intervals for the parameters. The intervals were directly obtained from the marginal a posteriori distribution of parameters.

Since the Gibbs sampler is an iterative algorithm, it is necessary checking its convergence. Such convergence was confirmed in the current study by applying the criteria by Heidelberger and Welch (1983) and Raftery and Lewis (1992), which were implemented in the Bayesian Output Analysis (BOA) package of the R software (The R Foundation 2017).

The Bayesian adaptability and stability analysis applied to each parameter of the herein adopted regression model took into consideration 250.000 iterations in the Gibbs sampler algorithm based on a burn-in period of 10.000 iterations. The spacing between points sampled from five iterations (thinning) was taken into consideration to find an uncorrelated sample, and it resulted in samples of the marginal a posteriori distributions of each parameter; the inference of each parameter was based on such distributions.

\section{Results and discussion}

Overall, all chains achieves convergence, since the Raftery and Lewis (1992) dependency factor provided values lower than five, and the $p$ value of the Heidelberger and Welch test Heidelberger and Welch (1983), which to test if the length of the sample is enough to estimate the mean with sufficient accuracy, was always higher than the 5\% level of significance.

The significance of the variation sources has shown substantial differences between genotypes and environments (Table 2). The significant result between genotypes and environments (GxE) has indicated different cultivar behaviors in different environments. Significant GxE interaction effects were also reported in several studies about maize genotypes in different Brazilian regions (Engelsing et al. 2012; Carvalho et al. 2013; Storck et al. 2014). This significant interaction is one of the greatest challenges for genotype selection, since it makes it difficult identifying effectively superior genotypes. The occurrence of these variations has led to the need of conducting a detailed study about genotypes' behavior in different environments, based on adaptability and stability analyses.

The adaptability and stability parameters were found by considering values derived from the frequentist analysis as a priori information, along with their respective credible intervals, as shown in Table 3.

Table 2 Estimates of the mean yield squares of 25 hybrid maize genotypes assessed in 22 environments

\begin{tabular}{llc}
\hline Sources of variation & df & \multicolumn{1}{c}{ Mean square } \\
\hline Genotypes (G) & 24 & $16,241,031.01^{* *}$ \\
Environments (E) & 21 & $114,448,699.64 * *$ \\
Genotypes $\times$ environments (GxE) & 504 & $2,454,247.71^{* *}$ \\
Residue & 528 & $708,660.56$ \\
MS $>/$ MS $<$ & - & 5.92 \\
\hline
\end{tabular}

**Significant at 0.01 probability levels by $\mathrm{F}$ test 
Table 3 Stability and adaptability estimates found through the methodology by Eberhart and Russell (1966)

\begin{tabular}{|c|c|c|c|c|}
\hline \multirow[t]{2}{*}{ Genotypes } & \multirow[t]{2}{*}{ Mean } & \multicolumn{2}{|c|}{ Eberhard and Russell (1966) } & \multirow[t]{2}{*}{$\overline{\mathrm{R}^{2}}$} \\
\hline & & $\beta 1 \mathrm{i}$ & $\delta^{2} \mathrm{~d}$ & \\
\hline 30 A 68 HX & $9402 \mathrm{a}$ & 1.03 & $850,431.38 * *$ & 70 \\
\hline 2 B 707 HX & $9301 \mathrm{a}$ & $1.20 *$ & $684,693.98 * *$ & 78 \\
\hline 30 A 16 HX & $9287 \mathrm{a}$ & $1.49 * *$ & $597,704.35 * *$ & 86 \\
\hline 2 B 587 HX & $9192 \mathrm{a}$ & $1.29 * *$ & $314,451.11 * *$ & 87 \\
\hline 2 B $710 \mathrm{HX}$ & $9150 \mathrm{a}$ & 1.02 & $103,367.25 * *$ & 85 \\
\hline 2 B $604 \mathrm{HX}$ & $9146 \mathrm{a}$ & $1.19 *$ & $495,764.81 * *$ & 81 \\
\hline 30 A 37 HX & $9124 \mathrm{a}$ & 1.13 & $255,791.43$ & 85 \\
\hline 30 A 95 HX & $8992 \mathrm{a}$ & $1.21 *$ & $786,791.73 * *$ & 77 \\
\hline 2 B 433 HX & $8932 b$ & 1.06 & $-27,025.11 * *$ & 90 \\
\hline P $4285 \mathrm{H}$ & $8907 b$ & $0.70 * *$ & $484,829.04 * *$ & 61 \\
\hline 20 A 55 HX & $8853 b$ & 1.13 & $119,157.46$ & 87 \\
\hline $30 \mathrm{~F} 53 \mathrm{HR}$ & $8833 b$ & $0.80^{*}$ & $131,892.45 * *$ & 50 \\
\hline AG $8041 Y G$ & $8743 b$ & $0.82 *$ & $444,286.36^{*}$ & 69 \\
\hline 30 A 91 HX & $8737 b$ & $1.18 *$ & $131,312.58$ & 88 \\
\hline 2 В 688 HX & $8736 b$ & $1.20 *$ & $649,181.43 *$ & 79 \\
\hline 20 A 78 HX & $8730 \mathrm{~b}$ & 1.11 & $681,658.41$ & 76 \\
\hline DKB 370 & $8640 \mathrm{~b}$ & 0.88 & $521,731.59 * *$ & 70 \\
\hline $30 \mathrm{~K} 73 \mathrm{H}$ & $8591 \mathrm{~b}$ & 1.00 & $394,714.43 * *$ & 78 \\
\hline DKB $330 \mathrm{YG}$ & $8579 b$ & 1.00 & $669,348.74 * *$ & 72 \\
\hline AS 1596 R2 & $8401 \mathrm{c}$ & 0.92 & $658,136.68 * *$ & 69 \\
\hline Statusvip & $8345 c$ & $0.77 * *$ & $649,673.59 * *$ & 61 \\
\hline BM 820 & $8275 \mathrm{c}$ & $0.80 *$ & $611,926.64 * *$ & 64 \\
\hline AS 1555 YG & $8098 \mathrm{c}$ & 0.95 & $467,038.09 * *$ & 74 \\
\hline BRS 2022 & $7428 d$ & $0.65 * *$ & $500,842.29 * *$ & 57 \\
\hline BRS 2020 & $7354 d$ & $0.47 * *$ & $737,313.21 * *$ & 35 \\
\hline
\end{tabular}

* and **significant at 0.05 and 0.01 probability levels, respectively

Only 2 (30A16HX and 2B587HX) out of the 25 genotypes assessed according to the Bayesian methodology in model M1 (informative priors) were classified as of specific adaptability to favorable environments $\left(\beta_{1 \mathrm{i}}>1\right)$ (Table 4). The hybrids P4285HX, BRS2022, 30A91HX and BRS2020 were classified as of specific adaptability to unfavorable environments $\left(\beta_{1 \mathrm{i}}<1\right)$. The other genotypes were considered of general adaptability and showed adaptability parameters within the $95 \%$ credible interval range. All genotypes have presented stability parameter $\left(\sigma_{d i}^{2}\right)$ values higher than 0 and were considered of low predictability within the $95 \%$ credible interval range.
The M2 (non-informative priors) analysis has applied the same criteria used to classify the genotypes in $\mathrm{M} 1$, i.e., the $95 \% \mathrm{CI}$ range.

The $\beta_{1 \mathrm{i}}$ and $\sigma_{d i}^{2}$ estimates for all hybrids in M2 were equivalent to the M1 analysis results. These results do not corroborate those reported by Nascimento et al. (2011), Couto et al. (2015) and Teodoro et al. (2015), whose priors' information derived from the application of the meta-analysis technique, i.e., the data used in the analysis came from previous studies. However, Nascimento et al. (2011) have stated that more accurate results can be found in adaptability and stability studies that have more information available for meta-analysis.

The Bayes factor, which is a method that compares model 1 to model 2, has presented the lowest estimate value (18.36) in the analysis of the Statusvip genotype, as well as the highest estimate value (20.59) in the analysis of the 2B433HX genotype (Table 5).

These results have shown that, although the adaptability and stability parameter estimates of the two models presented similar results, M1 has shown the highest fit quality because it met the $10 \leq \mathrm{BF}_{\mathrm{ij}}<30$ intervals. Thus, the Bayes factor has shown that higher accuracy can be achieved when informative priors are used to build the Model. In addition, the insertion of a priori information in Model 1 has generated smaller credible interval ranges in comparison to Model 2, fact that reinforced the greater accuracy in the estimation of parameters and, consequently, in a more reliable genotype selection.

The results of the frequentist analysis, which enabled the a priori inferences, has shown great divergence from the Bayesian approach results. Among the genotypes classified as of specific adaptability to favorable environments $\left(\beta_{1 \mathrm{i}}<1\right)$ 30A68HX, 2B707HX, 2B587HX, 2B604HX, 2B710HX, 2B710HX, 2B710HX, 2B $433 \mathrm{HX}$, 20A55HX, 20A78HX, 2B688HX, 30K73H and DKB330YG-only 2B587HX complied with the adaptability results found through the Bayesian procedure. It has also disagreed with the stability classification, which was high for this genotype, according to the frequentist analysis.

The 30A16HX cultivar was considered of great adaptability and high predictability, fact that disagree with the Bayesian approach, which classified it as of specific adaptability to favorable environments and of 
Table 4 Estimates of the a posteriori mean $\left(\bar{\beta}_{0 i}\right)$ and of the credible intervals $(95 \%)$ of the adaptability $\left(\bar{\beta}_{1 i}\right)$ and stability $\left(\bar{\sigma}_{d i}^{2}\right)$ parameters, by taking into consideration informative and non-informative priors for maize hybrids

\begin{tabular}{|c|c|c|c|c|c|c|c|c|c|}
\hline Genotypes & LI $\bar{\beta}_{0 i}$ & $\bar{\beta}_{0 i}$ & $\operatorname{LS} \bar{\beta}_{0 i}$ & LI $\bar{\beta}_{1 i}$ & $\bar{\beta}_{1 i}$ & $\operatorname{LS} \bar{\beta}_{1 i}$ & $\mathrm{LI} \bar{\sigma}_{i}^{2}$ & $\bar{\sigma}_{d i}^{2}$ & $\mathrm{LS} \bar{\sigma}_{d i}^{2}$ \\
\hline \multicolumn{10}{|c|}{ Informative priors } \\
\hline 30A68HX & 9416.08 & 9463.89 & 9511.36 & 0.73 & 1.04 & 1.34 & $311,899.62$ & $887,359.99$ & $1,935,057.20$ \\
\hline $30 \mathrm{~A} 16 \mathrm{HX}$ & 9382.74 & 9430.41 & 9477.79 & 1.35 & 1.61 & 1.87 & $117,565.66$ & $526,297.11$ & $1,270,207.50$ \\
\hline 2B707HX & 9238.99 & 9286.75 & 9334.20 & 0.93 & 1.21 & 1.49 & $225,864.34$ & $727,687.02$ & $1,640,833.00$ \\
\hline 2B587HX & 9151.92 & 9199.34 & 9246.51 & 1.13 & 1.34 & 1.55 & $-51,770.34$ & $211,236.70$ & $692,476.20$ \\
\hline 30A37HX & 9146.36 & 9193.89 & 9241.16 & 0.97 & 1.20 & 1.43 & $10,629.24$ & $327,298.87$ & $904,565.90$ \\
\hline 2B604HX & 9144.73 & 9192.48 & 9239.91 & 0.95 & 1.23 & 1.51 & $201,790.21$ & $682,954.25$ & $1,558,560.70$ \\
\hline 2B710HX & 9133.03 & 9180.48 & 9227.66 & 0.85 & 1.06 & 1.27 & $-43,194.16$ & $227,209.23$ & $721,929.40$ \\
\hline 30A95HX & 9025.42 & 9073.28 & 9120.80 & 0.93 & 1.26 & 1.59 & $442,877.91$ & $1,130,403.57$ & $2,383,595.30$ \\
\hline $\mathrm{P} 4285 \mathrm{H}$ & 9006.77 & 9054.46 & 9101.85 & 0.42 & 0.69 & 0.95 & $140,969.12$ & $569,779.12$ & $1,350,301.20$ \\
\hline 30F53HR & 8959.88 & 9007.78 & 9055.33 & 0.43 & 0.78 & 1.14 & $609,719.54$ & $1,439,328.15$ & $2,950,703.90$ \\
\hline 2B433HX & 8912.67 & 8959.75 & 9006.56 & 0.86 & 1.03 & 1.20 & $-167,182.45$ & -3612.86 & $295,831.70$ \\
\hline 20A55HX & 8786.16 & 8833.55 & 8880.66 & 0.94 & 1.14 & 1.35 & $-71,742.43$ & $173,993.29$ & $623,656.90$ \\
\hline 20A78HX & 8768.06 & 8815.87 & 8863.34 & 0.84 & 1.14 & 1.44 & $310,156.49$ & $884,139.39$ & $1,929,113.10$ \\
\hline DKB370 & 8708.17 & 8755.89 & 8803.31 & 0.61 & 0.88 & 1.15 & $169,379.90$ & $622,651.69$ & $1,447,705.50$ \\
\hline 2B688HX & 8707.50 & 8755.21 & 8802.62 & 0.98 & 1.25 & 1.52 & $161,845.34$ & 608682.56 & $1,421,914.60$ \\
\hline AG8041YG & 8696.20 & 8743.87 & 8791.23 & 0.59 & 0.85 & 1.11 & $119,565.53$ & $529,657.49$ & $1,277,164.00$ \\
\hline $30 \mathrm{~K} 73 \mathrm{H}$ & 8682.75 & 8730.50 & 8777.94 & 0.81 & 1.09 & 1.37 & $201,007.43$ & $681,462.55$ & $1,555,662.60$ \\
\hline DKB330YG & 8426.20 & 8474.05 & 8521.56 & 0.72 & 1.05 & 1.38 & $427,583.11$ & $1,102,070.29$ & $2,331,325.70$ \\
\hline AS1596R2 & 8314.25 & 8362.05 & 8409.51 & 0.59 & 0.89 & 1.19 & $291,091.25$ & $848,739.54$ & $1,863,742.80$ \\
\hline BM820 & 8220.55 & 8268.32 & 8315.76 & 0.56 & 0.84 & 1.13 & $223,355.24$ & $723,056.76$ & $1,632,220.90$ \\
\hline AS1555YG & 7942.64 & 7990.41 & 8037.86 & 0.62 & 0.91 & 1.20 & $242,445.36$ & $758,502.57$ & $1,697,529.60$ \\
\hline Statusvip & 7729.26 & 7777.25 & 7824.89 & 0.49 & 0.96 & 1.44 & $1,564,416.33$ & $3,204,913.43$ & $6,183,297.30$ \\
\hline BRS2022 & 7527.46 & 7575.03 & 7622.33 & 0.43 & 0.66 & 0.90 & $33,436.37$ & $369,834.02$ & $982,831.10$ \\
\hline 30A91HX & 7437.66 & 7485.55 & 7533.10 & 0.12 & 0.47 & 0.83 & $605,087.04$ & $1,430,747.35$ & $2,934,813.60$ \\
\hline BRS2020 & 7418.13 & 7465.68 & 7512.97 & 0.19 & 0.42 & 0.66 & $23,700.53$ & $351,619.57$ & $949,326.40$ \\
\hline \multicolumn{10}{|c|}{ Non-informative priors } \\
\hline 30A68HX & 8913.71 & 9407.22 & 9887.84 & 0.71 & 1.04 & 1.37 & $338,403.17$ & $968,784.33$ & $2,128,015.90$ \\
\hline 30A16HX & 8976.40 & 9390.35 & 9795.92 & 1.33 & 1.61 & 1.88 & $135,996.96$ & $581,887.80$ & $1,401,014.20$ \\
\hline 2B707HX & 8778.78 & 9238.29 & 9687.48 & 0.90 & 1.21 & 1.52 & $248,651.39$ & $797,372.50$ & $1,805,782.60$ \\
\hline 2B587HX & 8843.71 & 9174.22 & 9500.04 & 1.12 & 1.34 & 1.57 & $-40,243.16$ & $245,598.89$ & $770,422.60$ \\
\hline 30A37HX & 8913.71 & 9407.22 & 9887.84 & 0.71 & 1.04 & 1.37 & $338,403.17$ & $968,784.33$ & $2,128,015.90$ \\
\hline 2B604HX & $8696.873+\mathrm{J} 8$ & 9146.50 & 9586.56 & 0.93 & 1.23 & 1.53 & $223,436.49$ & $749,391.27$ & $1,716,256.30$ \\
\hline 2B710HX & 8819.62 & 9154.71 & 9485.00 & 0.83 & 1.06 & 1.28 & $-31,330.75$ & $262,608.07$ & $802,157.10$ \\
\hline 30A95HX & 8468.50 & 9008.34 & 9533.29 & 0.90 & 1.26 & 1.62 & $475,026.41$ & $1,229,569.04$ & $2,615,132.80$ \\
\hline $\mathrm{P} 4285 \mathrm{H}$ & 8590.30 & 9014.10 & 9429.46 & 0.41 & 0.69 & 0.97 & $160,247.10$ & $628,201.21$ & 1487562.40 \\
\hline 30F53HR & 8336.09 & 8929.92 & 9505.58 & 0.39 & 0.78 & 1.18 & $649,052.18$ & $1,562,314.35$ & $3,241,610.60$ \\
\hline 2B433HX & 8684.77 & 8944.56 & 9201.53 & 0.85 & 1.03 & 1.20 & $-160,363.61$ & $17,063.95$ & $342,653.70$ \\
\hline 20A55HX & 8491.74 & 8811.01 & 9126.02 & 0.93 & 1.15 & 1.36 & $-61,117.26$ & $205,882.75$ & 695680.50 \\
\hline 20A78HX & 8271.50 & 8763.24 & 9243.72 & 0.81 & 1.14 & 1.47 & $336,355.29$ & $964,741.14$ & 2120765.70 \\
\hline DKB370 & 8278.96 & 8714.64 & 9141.67 & 0.59 & 0.88 & 1.17 & $189,798.37$ & $684,594.79$ & 1593382.90 \\
\hline 2B688HX & 8281.95 & 8714.55 & 9138.65 & 0.97 & 1.25 & 1.54 & $181,918.21$ & $669,653.25$ & 1565143.20 \\
\hline AG8041YG & 8329.97 & 8743.71 & 9149.69 & 0.57 & 0.85 & 1.13 & $136,819.85$ & $583,467.75$ & $1,403,600.10$ \\
\hline $30 \mathrm{~K} 73 \mathrm{H}$ & 8238.08 & 8686.90 & 9126.67 & 0.79 & 1.09 & 1.39 & $222,851.07$ & $747,507.70$ & $1,711,321.20$ \\
\hline
\end{tabular}


Table 4 continued

\begin{tabular}{llllllllrr}
\hline Genotypes & LI $\bar{\beta}_{0 i}$ & $\bar{\beta}_{0 i}$ & LS $\bar{\beta}_{0 i}$ & LI $\bar{\beta}_{1 i}$ & $\bar{\beta}_{1 i}$ & LS $\bar{\beta}_{1 i}$ & LI $\bar{\sigma}_{i}^{2}$ & $\bar{\sigma}_{d i}^{2}$ & LS $\bar{\sigma}_{d i}^{2}$ \\
\hline DKB330YG & 7880.92 & 8414.58 & 8935.10 & 0.70 & 1.05 & 1.41 & $458,960.20$ & $1,198,374.09$ & $2,558,804.10$ \\
AS1596R2 & 7829.70 & 8313.57 & 8787.54 & 0.57 & 0.89 & 1.21 & $316,346.87$ & $926,411.22$ & $2,046,826.90$ \\
BM820 & 7767.90 & 8225.38 & 8673.86 & 0.54 & 0.85 & 1.15 & $246,014.87$ & $791,742.77$ & $1,793,407.30$ \\
AS1555YG & 7483.03 & 7947.56 & 8403.25 & 0.60 & 0.91 & 1.22 & $265,974.04$ & $829,505.07$ & $1,864,084.20$ \\
Statusvip & 6804.04 & 7644.35 & 8451.20 & 0.41 & 0.96 & 1.52 & $164,9167.25$ & $3,474,136.65$ & $6,841,080.20$ \\
BRS2022 & 7175.07 & 7548.57 & 7917.12 & 0.41 & 0.66 & 0.91 & $48,362.98$ & $414,210.74$ & $1,085,415.40$ \\
30A91HX & 6831.42 & 7421.24 & 7997.40 & 0.08 & 0.48 & 0.87 & $643,672.46$ & $1,550,486.30$ & $3,218,416.80$ \\
BRS2020 & 7071.74 & 7440.27 & 7804.20 & 0.18 & 0.43 & 0.67 & $38,193.37$ & $394,773.24$ & $1,048,826.20$ \\
\hline
\end{tabular}

Table 5 Bayes factor estimates obtained through the comparison between models using informative (i) and non-informative priors (j) for maize hybrids

\begin{tabular}{|c|c|}
\hline Genotypes & $F B_{i j}$ \\
\hline 2B433HX & 20.59 \\
\hline 2B587HX & 20.56 \\
\hline $30 \mathrm{~A} 16 \mathrm{HX}$ & 20.55 \\
\hline 2B710HX & 20.53 \\
\hline 30A37HX & 20.46 \\
\hline 30A68HX & 20.40 \\
\hline 2B707HX & 20.31 \\
\hline 20A55HX & 20.27 \\
\hline 2B604HX & 20.24 \\
\hline $\mathrm{P} 4285 \mathrm{H}$ & 20.18 \\
\hline 30A95HX & 19.94 \\
\hline AG8041YG & 19.94 \\
\hline 2B688HX & 19.89 \\
\hline DKB370 & 19.88 \\
\hline $30 \mathrm{~K} 73 \mathrm{H}$ & 19.83 \\
\hline 20A78HX & 19.81 \\
\hline 30F53HR & 19.78 \\
\hline AS1596R2 & 19.44 \\
\hline DKB330YG & 19.43 \\
\hline BM820 & 19.42 \\
\hline AS1555YG & 19.17 \\
\hline BRS2022 & 19.07 \\
\hline BRS2020 & 19.01 \\
\hline 30A91HX & 18.53 \\
\hline Statusvip & 18.36 \\
\hline
\end{tabular}

low predictability. Only two (P4285H and BRS2022) out of the eight genotypes considered of specific adaptability to unfavorable environments $(\beta 1>1)$ have shown results agreeing with the Bayesian inference ones. The 30A91HX and BRS2020 cultivars were considered of great adaptability, according to the frequentist analysis, and of specific adaptability to unfavorable environments, according to the Bayesian methodology.

The disagreement between results often derives from the frequentist model tendency to classify the genotypes as of specific adaptability to favorable or unfavorable environments, thus compromising the reliable recommendation of these genotypes.

Thus, the Bayesian approach provides more accuracy and allows producing more reliable results to indicate genotypes. Consequently, it allows producers to increase the yield and reduce economic losses.

\section{Conclusions}

Using the Bayesian approach in adaptability and stability studies provides greater accuracy to the selection of hybrid maize genotypes.

The 30A16HX and 2B587HX genotypes were classified as of specific adaptability to favorable environments, based on informative priors.

The P4285HX, BRS2022, 30A91HX and BRS2020 genotypes have shown specific adaptability to unfavorable environments.

The results derived from the use of informative a priori distributions have shown greater adjust accuracy than those derived from non-informative a priori distributions, according to the Bayes factor models.

Acknowledgements To CAPES for the grant provided and to EMBRAPA for infrastructures and resources necessary for the realization of this study. 


\section{References}

Almeida TE, Hennequin S, Schneider H, Smith AR, Batista JAN, Ramalho AJ, Proite K, Salino A (2016) Towards a phylogenetic generic classification of Thelypteridaceae: additional sampling suggests alterations of neotropical taxa and further study of paleotropical genera. Mol Phylogenet Evol 94:688-700. https://doi.org/10.1016/j.ympev.2015. 09.009

Backes RL, Elias HT, Hemp S, Nicknich W (2005) Adaptabilidade e estabilidade de genótipos de feijoeiro no estado de Santa Catarina. Acta Sci Agron 27:309-314

Bastiaansen JWM, Coster A, Calus MPL, Arendonk JAMV, Bovenhuis H (2012) Long-term response to genomic selection: effects of estimation method and reference population structure for different genetic architectures. Genet Sel Evol 44:3. https://doi.org/10.1186/1297-968644-3

Carvalho EV, Afférri FS, Dotto MA, Peluzio JM, Cancellier LL, Santos WF (2013) Adaptability and stability of corn hybrids in Tocantins. J Biotechnol Biodivers 4:25-31

Cotes JM, Crossa J, Sanches A, Cornelius PA (2006) A Bayesian approach for assessing the stability of genotypes. Crop Sci 46:2654-2665. https://doi.org/10.2135/cropsci2006.04. 0227

Couto MF, Nascimento M, Amaral Junior AT, Silva FF, Viana AP, Vivas M (2015) Eberhart and Russel's Bayesian method in the selection of popcorn cultivars. Crop Sci 55:571-577. https://doi.org/10.2135/cropsci2014.07.0498

Cruz CD (2006) Programa genes: biometria. UFV, Viçosa

Cruz CD, Torres RAA, Vencovsky R (1989) An alternative approach to the stability analysis proposed by Silva and Barreto. Rev Bras Genét 12:567-580

Eberhart SA, Russell WA (1966) Stability parameters for comparing varieties. Crop Sci 6:36-40. https://doi.org/10. 2135/cropsci1966.0011183X000600010011x

Engelsing MJ, Coimbra JLM, Vale NM, Barli LD, Jussara CS, Guidolin AF, Bertoldo JG (2012) Adaptabilidade e estabilidade em milho: rendimento de grãos $\times$ severidade de cercosporiose. Revista de Ciências Agroveterinárias 11:106-117

Hartley HO (1950) The use of range in analysis of variance. Biometrika 37:271-280

Heidelberger P, Welch PD (1983) Simulation run length control in the presence of an initial transient. Oper Res 31:1109-1144. https://doi.org/10.1287/opre.31.6.1109

Jeffreys H (1961) Theory of probability, 3rd edn. Clarendon Press, Oxford

Kass RE, Raftery AE (1995) Bayes factors. J Am Stat Assoc 90:773-795. https://doi.org/10.1080/01621459.1995. 10476572

Kitada S, Hayashi T, Kishino H (2000) Empirical Bayes procedure for estimating genetic distance between populations and effective population size. Genetics 156:2063-2079

Lin CS, Binns MR (1988) A superiority measure of cultivar performance for cultivars $\times$ location data. Can J Plant Sci 68:193-198
Macedo LR, Cecon PR, Silva FF, Nascimento M, Puiatti GA, Oliveira ACR, Puiatti M (2017) Bayesian inference for the fitting of dry matter accumulation curves in garlic plants. Pesqui Agropecu Bras 52:572-581. https://doi.org/10. 1590/s0100-204x2017000800002

Mendes FF, Guimarães LJM, Souza JC, Guimarães PEO, Pacheco CAP, Machado JRA, Meirelles WF, Silva AR, Parentoni SN (2012) Adaptability and stability of maize varieties using mixed model methodology. Crop Breed Appl Biotechnol 12:111-117. https://doi.org/10.1590/ S1984-70332012000200003

Molina RLM, Sanche A, Cotes TJM (2012) Inferência bayesiana na análise de testes regionais de arroz em dois sistemas de cultivo. Rev Fac Nac Agron 64:5883-5891. https://doi. org/10.15446/rfnam

Nascimento M, Silva FF, Sáfadi T, Nascimento ACC, Ferreira PF, Cruz CD (2011) Abordagem bayesiana para avaliação da adaptabilidade e estabilidade de genótipos de alfafa. Pesq Agropec Bras 46:26-32. https://doi.org/10.1590/ S0100-204X2011000100004

R Foundation (2017) R: the R project for statistical computing. https://www.r-project.org/. Accessed 26 Aug 2017

Raftery AE, Lewis SM (1992) Comment: one long run with diagnostics: implementation strategies for Markov chain Monte Carlo. Stat Sci 7:493-497. https://doi.org/10.1214/ ss/1177011143

Resende MDV (2000) Inferência bayesiana e simulação estocástica (amostragem de gibbs) na estimação de componentes de variância e de valores genéticos em plantas perenes. Embrapa Florestas, Colombo

Resende MDV, Duda LL, Guimarães PRB, Fernandes JSC (2001) Análise de modelos lineares mistos via inferência Bayesiana. Rev Mat Esta 19:41-70

Silva LC, Benavides YA (2001) El enfoque bayesiano: otra manera de inferir. Gac Sanit 15:341-346

Storck L, Cargnelutti Filho A, Guadagnin JP (2014) Análise conjunta de ensaios de cultivares de milho por classes de interação genótipo $\times$ ambiente. Pesq Aropec Bras 9:163-172. 204X2014000300002

Teodoro PE, Nascimento M, Torres FE, Barroso LMA, Sagrilo E (2015) Perspectiva bayesiana na seleção de genótipos de feijão-caupi em ensaios de valor de cultivo e uso. Pesq Aropec Bras 50:878-885. https://doi.org/10.1590/S0100204X2015001000003

The R Foundation (2010) R: the R project for statistical computing. https://www.r-project.org. Accessed 05 April 2017

Verma VMM, Chahal GS, Murty BR (1978) Limitations of conventional regression analysis a proposed modification. Theor Appl Genet 53:89-91. https://doi.org/10.1007/ BF00817837

Wang Q, Wei J, Pan T, Xu S (2016) An efficient empirical Bayes method for genomewide association studies. J Anim Breed Genet 133:253-263. https://doi.org/10.1111/jbg.12191 